\title{
Collaborative leadership with a focus on stakeholder identification and engagement and ethical leadership: a dental perspective
}

\author{
Bhaven Modha'
}

\section{Key points}

In these times and beyond, embracing mutually beneficial relationships based on trust, integrity and empowerment shall be more important than ever; therefore, there is a great need for collaborative leadership within the dental profession.
An awareness of, and ability to use, the traditional practices of stakeholder identification and engagement as well as ethical leadership may allow dental organisations and professionals to better exercise collaborative leadership.
Alike with clinical knowledge and skills, dental organisations and professionals must self-reflect on their own leadership capabilities, be selfaware of their strengths and weaknesses, and aspire to improve themselves accordingly.

\begin{abstract}
The dental profession is susceptible to change. In order to cope and adapt, individuals and organisations will need to work together, now more than ever. One approach that may be beneficial in these times, and beyond, is collaborative leadership. This is where a mutually beneficial relationship is established between two or more parties, who work towards common goals by sharing authority, responsibility and accountability for achieving results. When groups of individuals look beyond their personal interests and instead collaborate, they may channel their efforts to successfully achieve shared goals. However, for this to be fruitful, stakeholders (to include different individuals or groups that have a vested interest) will need to be identified and engaged, and ethical values based on the objectives of the organisation and those advocated by professional and regulatory bodies must be upheld. This paper explores how the traditional practices of stakeholder identification and engagement, as well as ethical leadership, may be of relevance in attaining success through the contemporary collaborative leadership approach.
\end{abstract}

\section{Introduction}

Leadership is defined as a 'process of influencing others to understand and agree about what needs to be done and how to do it, and the process of facilitating individual and collective efforts to accomplish shared objectives.' ${ }^{1}$ This proposes that leadership encompasses several elements: a process; influencing others; working efficiently with others; sharing goals with others; and collectively attaining these goals. With regards to the dental profession, it has been asserted that during challenging times, there has been a shortage of 'strong, proactive leadership' which has led to feelings of 'professional disillusionment.' ${ }^{2}$ Dentistry itself has been described as having a history of

'Whittington Health NHS Trust, Grand Union Village Health Centre, Dental Department - Second Floor, Taywood Road, Northolt, Middlesex, UB5 6LW, England, UK.

Correspondence to: Bhaven Modha

Email address: b.modha@nhs.net

Refereed Paper.

Accepted 3 December 2020

https://doi.org/10.1038/s41415-021-3457-2 hierarchical control and central direction ${ }^{3}$ and a 'core ideology of self-interest.' ${ }^{4}$ A professional with a manner of self-interest may be perceived as someone that 'incessantly seeks more power and acquisition of material possessions. ${ }^{5}$

Hierarchical control, central direction and selfinterest are typical of authoritarian or autocratic leadership. ${ }^{6}$ Such a historical approach establishes a clear division between leaders and followers. Leaders are positioned at the top or in the centre, while followers are below or within the surroundings, and control operates from 'topdown' or from the 'centre outwards'. Leaders have an absolute control over the followers; a full command over all decisions; set strict rules and control processes; formulate choices based on their own ideas and judgements; uphold formal, professional relationships; rarely permit or accept any input; and penalise followers for mistakes. ${ }^{67,8}$

As a last resort, autocratic leadership might be applicable in situations involving severe time pressures, where followers are unskilled or unmotivated, or when there is little margin for error. If misused for self-aggrandisement, self-serving or exploiting followers for personal gain, then autocratic leadership can produce the more sinister despotic leadership. ${ }^{9}$ This involves: disregarding followers' needs and concerns; holding followers in a somewhat unquestioning submission; employing monopolising schemes to manipulate followers; and indulging in morally corrupt behaviour. ${ }^{10}$ Relatedly, one article has suggested that some general dental practitioners could be in a clique with commissioners, therefore possessing the benefit of exploiting this relationship for their own self-interest. ${ }^{11}$ Another article states that 'some less than ethical colleagues use the NHS brand to get people through the door and then "upsell" private treatments.' ${ }^{12}$

Leadership development in dentistry has been described as 'highly neglected' when compared to non-health sectors including global enterprise, higher education and even football. ${ }^{13}$ However, in recent years, the topic of 'leadership and dentistry' has seen an increase in both scholarly literature and professional activities, and the subject continues to attract much due interest. Despite such efforts, the dental profession still faces some pressing 
issues, a few of which shall be touched upon within this paper.

The opposite of a historic autocratic and despotic type of leadership could be a contemporary one that promotes equality and inclusivity. It would further involve embracing diversity and working together cordially (that is, leading collaboratively); appreciating all teammates and meeting their needs (that is, identifying stakeholders); maintaining genuine and constructive relations with all teammates (that is, engaging stakeholders); and following ethical principles to inspire admirable behaviour (that is, leading ethically). The purpose of this paper is to shed light on how collaborative leadership may be achieved by - and through - stakeholder identification and engagement, as well as ethical leadership, with reference to the UK's dental profession.

\section{Collaborative leadership}

It has been long affirmed that dental professionals are part of a dental team and that teamwork is an integral component within the profession. ${ }^{14}$ Yet, it is still reported that many dentists are lonely and isolated. ${ }^{15,16}$ Bringing together a group of highly skilled professionals may, therefore, not guarantee an efficient team or that a person will feel part of that team. This thought is echoed by the FDI World Dental Federation, who state that 'collaborative practice is more than just collaboration. ${ }^{17}$

Within a team, teammates' behaviours can be classed as either 'taskwork' or 'teamwork' processes. Taskwork involves performing core technical competencies (that is, clinical procedures). Teamwork involves the assortment of interactive and interdependent behavioural processes between teammates, which transform team inputs (that is, teammate characteristics and teammate composition) into outcomes (that is, teammate satisfaction and team performance). Within teamwork, each teammate has their own definite role and assigned duties that contribute towards the overall goal. ${ }^{18,19,20}$ For teamwork to be successful, there may need to be a fine balance between both taskwork (that is, clinical work) and teamwork processes (that is, interpersonal communication), and the presence of a team leader.

Collaboration considers the sharing of roles and responsibilities among the individuals within a group. Unlike teamwork, collaboration does not necessarily require a leader, as leadership is shared or distributed throughout the group. ${ }^{21}$ However, complex situations could arise that necessitate a leader. In such cases, a competent teammate might temporarily assume the role of a collaborative leader. Collaborative leadership (CL) is defined as 'a mutually beneficial relationship between two or more parties, who work toward common goals by sharing responsibility, authority and accountability for achieving results'; its theory postulates that when groups of individuals look beyond their own personal interests, and instead work together, they can channel their efforts to successfully reach shared goals. ${ }^{22}$

Core values of $\mathrm{CL}$ include: building authentic relationships, instead of expecting these to occur instinctively; understanding that nobody has full power over a situation, thus renouncing egotism and control; instilling trust and respect in everyone; developing a wide-ranging skillset to handle different situations; using adversities to take creative yet sensible risks; rejecting silos, a 'my work - your work' mentality, and a blame culture; employing decentralised, flat hierarchies that consider leaders and followers as equals; forming teams with teammates that have different levels of knowledge and skills, so that diverse perspectives can be explored; improving decisiveness by avoiding partisan or biased choices; fostering an openness to feedback and communication; setting well-defined goals with teammates; and incorporating teammates' contributions into planning and decision-making processes, so that everyone can feel part of the organisation. Disadvantages of CL may include: the need for dedicated commitment; an inability to adapt from a teamwork to a collaborative way of work; encountering situations that may demand a formal leader; lengthier processes; incurring challenges if mismanaged; and misreading collaboration as a consensus type of management. .22,23,24,25 $^{2}$

Collaboration is growing in prominence and many scholars suggest its use within dentistry. ${ }^{26,27,28,29}$ Recent examples of crossorganisational collaboration include: different dental bodies coming together to devise an Education, Ethics and Dental Team Working Group to investigate the matter of environmentally sustainable dentistry; ${ }^{30}$ a COVID-19 Future Planning Task Group to formulate 'return to work' guidelines; ${ }^{31}$ and a Diversity in Dentistry Action Group to confront equality, diversity and inclusivity disparities. ${ }^{32}$ Internationally, some dental organisations have united to combat poor child oral health worldwide; the virtues of $\mathrm{CL}$ are thought to have been a cornerstone of this venture. ${ }^{13}$ One American study has shown that CL had a substantial impact on dental students' willingness to raise concerns and make suggestions; the researchers recommend that team leaders within dental educational establishments should be encouraged to use CL. ${ }^{33}$

$\mathrm{CL}$, henceforth, presents many positive opportunities for the dental profession. For instance, interprofessional collaboration between dental providers and pharmacists to help patients manage chronic dental pain, ${ }^{34}$ especially amidst the current COVID-19 pandemic, where access to dental care may be lessened; interprofessional collaboration between medical and dental professionals, ${ }^{35}$ so that both groups may be able to reduce their frequency of prescribing antibiotics to patients for dental conditions; and crossorganisational collaboration between dental general anaesthesia services, primary care and community prevention teams, to help improve the dental needs of children and to reduce their need for dental treatment under general anaesthesia. $^{36}$

\section{The importance of stakeholder identification}

Within CL, forming synergistic relationships and shared goals with teammates is of paramount importance, but this may be unreachable if one does not know their stakeholders. Alike teammates and followers, stakeholders are individuals or groups that have a vested interest in an organisation's dealings, on either a personal, political or economic level. Stakeholders can be considered as either internal (that is, within the organisation: employees, managers and directors), or external (that is, outside of the organisation: patients, regulators, investors and manufacturers). The stakeholder theory advocates that anyone with a vested interest or stake in an organisation has a right to be treated as an influential member in the functioning of that organisation. Therefore, stakeholders can influence decision-making in a positive or negative way. ${ }^{37}$

Stakeholder identification processes can be utilised to better understand stakeholders from an organisational dimension. They should highlight each stakeholder's probable interests, benefits, effects, threats and any specific characteristics that are relevant. Stakeholders' opinions and interests can alter with time, so their attitudes and behaviours should be embedded into developmental plans to predict any possible difficulties. As organisational goals and strategies may be affected by deviations in the values of stakeholders, organisations must be perceptive and alert, taking note of such changes. ${ }^{38}$ One classification system categorises 
stakeholders into three distinctive levels, according to their degree of impact - the micro level (that is, parties involved at a practice level: dentists, dental care professionals, competitors, suppliers and waste collection services); the meso level (that is, management, funding bodies and groups that can affect professional behaviours: educational institutions, royal colleges, societies and indemnity organisations); and the macro level (that is, groups with the power to make decisions or impose change: governing bodies, regulatory bodies and policymakers). ${ }^{39}$

The advancement of 'do-it-yourselves' orthodontics has sparked controversy within the dental profession. Although such ventures may be advantageous for certain stakeholders, lucrative for the business owners, worthwhile for the digital technologists and potentially cheaper for patients, viable stakeholders (including the British Dental Association, Oral Health Foundation, British Orthodontic Society and some orthodontic professionals) have raised concerns about the potential risks of such treatment modality. ${ }^{40}$ From the outset, were these viable stakeholders identified? Was there any collaboration to decipher and evaluate these stakeholders' opinions, interests, benefits, effects, threats and changing perceptions? From a CL viewpoint, an early and thorough stakeholder identification process could be central to building trusting relationships and shared values with stakeholders, as well as in preventing conflict and barriers that might be caused by a failure to engage the expertise of key individuals.

\section{The importance of stakeholder engagement}

To enable productive collaborations, stakeholders will need to be successfully engaged with the organisation. Stakeholder engagement involves a two-way, iterative system between the organisation and the stakeholders. Here, communication, opinions and proposals flow in both directions. Resultantly, the organisation can learn about the perceptions, expectations and concerns of its stakeholders, and vice versa. Both parties can then utilise this information to make changes or improvements. Nonetheless, the success of this will be reliant on the organisation's ability to sustain long-term, symbiotic relationships, rather than conducting one-off consultations. ${ }^{41}$ For example, in a dental practice, teammates may well differ in terms of their work ethics, enthusiasm and involvement. Therefore, genuine collaborative efforts; regular communications and interactions with all teammates; team meetings and team-building exercises including all teammates; and oneto-one meetings and appraisals with each teammate may help to better involve, support, motivate and engage them.

With regards to collaboration, longestablished, well-defined taskwork-related roles and responsibilities of different dental professionals within a team could prevent a full sharing of these roles and responsibilities throughout the team. Of course, this shall be important for maintaining patients' and practice safety. However, by applying the core values of CL and sharing suitable procedures with competent, qualified members of the team (for instance, extended-duty dental nurses), this may strengthen collegial relations. Relatedly, one Scottish study that investigated skill mix use in a child oral health programme revealed that a 'lack of support from colleagues' acted as a barrier to dental nurses using their extended skills. ${ }^{42}$

One article from 2016 commented that some dental nurses felt 'undervalued, unsupported and paid unfairly. ${ }^{43}$ However, a recent article comments that some dental nurses feel a 'severe lack of support' and that many are 'leaving the profession. ${ }^{44}$ Had collaboration occurred to engage this stakeholder to ascertain and address their concerns and expectations at the appropriate micro, meso and macro levels? If so, were changes or improvements made that were mutually beneficial to all relevant stakeholders? The same questions may need to be asked with regards to the finding that 'nearly two-thirds of principal dentists and over half of all associate dentists across the UK often think of leaving dentistry', in the most recent 'Dentists' working patterns, motivation and morale' survey. ${ }^{45}$

The increase in patient awareness, expectations and demands, and a general rise in the litigious nature of society, might be contributing towards the surge in orthodontic allegations raised against registrants. ${ }^{46}$ To prevent such occurrences, and to ensure that patients receive optimal holistic care, perhaps there may need to be greater collaborative engagements with pertinent stakeholders to include: patients, other practitioners, educational bodies and one's self (that is: fully determining patients' needs and expectations, and managing these realistically; increasing coordination with colleagues and specialists to seek second opinions; referring patients to practitioners with more expertise; being selfaware of one's own limitations; continually self-reflecting and stipulating sensible learning needs; and undergoing necessary training and continuing professional development activities).

It has also been reported that an increasing proportion of complaints were made to the General Dental Council, where dental professionals have reported their colleagues or other registrants. ${ }^{47}$ Of course, if patient safety is at risk, then such action might be required. If otherwise, what may have prevented the stakeholders from engaging and resolving the issue at a local level? In a CL-type environment, perhaps fair, non-judgemental, 'open-door' discussions could better encourage stakeholders to engage with each other to resolve such issues, mediate conflicts and prevent escalations beyond the local level.

Having several, varying stakeholders that deliver diverse opinions can be challenging for collaboration. Stakeholder engagement may be further tested by a person belonging to many different stakeholder groups, each of which may have its own interests and be of a differing power. ${ }^{48}$ For instance, in a study that investigated dentists' views on the impact of direct access, respondents gave favourable views on the prospect of receiving referrals from dental hygienists and therapists for treatments beyond their scope of practice. However, the majority of respondents held unfavourable views about the overall implementation of direct access. ${ }^{49}$ Depending on the given situation, certain stakeholders may endorse their own principles or agendas, which could make it difficult to attain an authentic engagement; a compromise or negotiation might be required to help balance the interests of different stakeholders. ${ }^{48}$

\section{The importance of ethical leadership}

CL involves looking beyond personal interests and instead working together. This interrelates with the standard ethical principles, particularly beneficence: doing good to others and acting with kindness, mercy, charity and a moral obligation. ${ }^{50}$ Thus, using ethics to engage stakeholders, and to guide or lead teammates, could be vital to the success of CL. Ethical leadership proposes that leaders are in pursuit of attaining values that are morally correct and that leaders' decisions have an impact on others in the achievement of organisational goals. ${ }^{51}$ 
Its theory purports that leaders encourage followers to excel and overachieve; strive for social, environmental and financial success; and generate innovative practices. Such leadership can be applied in political contexts to enhance society. ${ }^{52}$ Qualities essential to ethical leadership include: empathy, integrity, honesty, humility, fairness, responsibility, collectivism, transparency, concern for stakeholders' wellbeing, interpersonal rapport building and empowerment. ${ }^{53,54}$ These traits resemble the core values of $\mathrm{CL}$, as well as the ethical attributes that dental professionals ideally need to have.

While dentistry continues to be a competitive field, especially within the private, cosmetic sector, practising ethically remains a fundamental obligation. Patients may well be one of the most crucial stakeholders; their needs and interests must be carefully identified and, of course, managed ethically. However, an upsurge in 'self-aggrandising advertisements and claims for egotistical, narcissistic dentistry, often promoted by younger, or apparently non-specialist dentists' has been reported. ${ }^{55}$ Some organisations and 'influencers' might also endorse questionable products or advertisements for a payment without making relevant conflict of interest declarations. ${ }^{56}$

Because these 'influencers' may appear to be popular and well connected, their exaggerated or non-evidence-based claims might pass unchallenged. ${ }^{56,57}$ This may also be the case when certain eminent organisations endorse dubious advertisements. ${ }^{12,57}$ Was there any form of collaboration with relevant stakeholders to identify their exact needs and interests, and if so, did these findings inform such 'influential' approaches? Are these types of engagements mutually beneficial to all stakeholders? Are such 'influencers' collaborative leaders? Have patients been given well-informed information that facilitates the engagement in a serious process of informed consent?

Alongside its advantages, social media usage is thought to be contributing towards increased comparisons, envy, low self-esteem, body dysmorphia and social anxiety. ${ }^{58}$ Advertising 'perfect smiles' or 'ideal' facial images on this domain might well attract followers (that is, some potential patients and the attention of some other clinicians). However, how may such advertising affect vulnerable viewers that could have a facial disfigurement or body dysmorphia condition relating to their teeth, mouth or face? Is such advertising an ethically collaborative engagement that considers all stakeholders' sensitivities? Relatedly, a recent study investigated the effect of viewing idealised smile images versus nature images via social media on the immediate facial satisfaction in young adults. This found that exposure to 'ideal' facial images on social media decreased facial satisfaction, with such effect being greater in those with high self-discrepancy scores. ${ }^{59}$

It has been reported that 'any cosmetic dentist on Instagram treats their patients as consumers' and that certain companies are actively encouraging clinicians to treat their patients as 'consumers. ${ }^{56}$ Cosmetic dentistry itself is not a recognised speciality, and crafting illusions of having specialist knowledge and using non-existent terms akin to 'perfect smiles', and self-descriptive designations such as 'cosmetic dentist' without specialist registration, could mislead patients. ${ }^{60,61}$ Relatedly, one article comments that the 'shameless promotion of rapid smiles and DIY aligners has regrettably turned our unsuspecting patients into mere "profit centres". ${ }^{62}$ Strategies involving the delivery of services for self-aggrandisement avarice or profiteering, rather than providing care in the patients' best interests, do not demonstrate CL; they instead demonstrate despotic leadership. With regards to CL, perhaps ethical traits of empathy, integrity and humility may better empower teammates (that is, patients) to accomplish shared goals (that is, completing mutually agreed treatment plans that are in the patients' best interests).

Owing to organisational failures being linked to the unethical actions of leaders and individuals, there has been an increase in the scholarly work of ethical leadership. ${ }^{63}$ However, one recent article outlines that there have been accusations of racism at a dental educational establishment, where Black and Minority Ethnic students 'have been subjected to racist language' from 'teaching staff, some students, and even patients. This article further states that there could be a 'wider issue of racism within the dentistry industry'. ${ }^{64}$ Discrimination ignores ethical principles and the core values of $\mathrm{CL}$, and it disregards stakeholder identification and engagement processes. Rather, promoting equality, diversity and inclusivity, which are key concepts of CL, would be far more advantageous.

Some studies, which explore leadership in an academic dentistry context, underline the need for dental educational establishments to obtain a complete integration into their university institutions and to cross-collaborate between different faculty departments. ${ }^{65,66,67}$ One English study highlights the importance of cross-faculty interprofessional education and collaboration between humanities, arts and clinical sciences. These subjects were integrated into the dental curriculum of an educational establishment, so that students could develop the tolerance of ambiguity. Activities involved close observation and group reading of texts, intent listening, and openly addressing obscurity and uncertainty. The researchers concluded that these activities may cultivate students' 'capacity to be the leaders and innovators of the future' and promote 'higher order skills.6 ${ }^{68}$ Perhaps, such innovative, collaborative endeavours might be a starting point for overcoming discriminatory habits at educational establishment and institutional levels.

\section{Conclusion}

'Leadership and dentistry' is a subject that may be further complicated by the multifaceted practice of dentistry, which encounters a dichotomy of interests between the provision of healthcare and generating a profit. CL appears to be refreshing and promising. However, if stakeholders with competing interests do not look beyond any differences or confinements, then these may act as barriers to fully engaging in collaborative pursuits. Thus, careful and tactful stakeholder identification and engagement processes might be critical to the success of CL.

Leadership extends beyond local, physical, organisational and clinical boundaries to include online, digital and social media realms, where teledentistry, virtual conferencing and dental advertising occur. Such innovations may promote effective collaborations: consulting patients and providing advice, and delivering educational programmes and ethical marketing ventures. However, dental organisations and professionals must be mindful of how their conduct and decisionmaking in such domains might impact on the quality of collaborative engagements with stakeholders, and likewise, the impact of these stakeholders in such domains.

In these uncertain, ever-changing, challenging times, and even thereafter, harnessing mutually beneficial relationships based on integrity, trust, confidence and other ethical virtues shall be more important than ever. Although CL might appear idealistic, there exists great potential for dental 
organisations and professionals to use a CL style that assimilates its core values and is adaptable according to the context. As per the foundations of CL, eradicating divisions and inequalities, and bringing together teammates, followers and stakeholders in a productive and ethical way, might help to form longlasting, harmonious relationships, where initiatives, strategies and goals can be shared for the common good of all people, and be implemented in the best interests of all people.

\section{Ethics declaration}

The author reports no conflicts of interest. The author alone is responsible for the article's content and writing.

\section{References}

1. Yukl G. Leadership in organisations. 6th ed. Upper Saddle River: Pearson-Prentice Hall, 2006.

2. Morison S, McMullan C. Preparing for the future: challenges and opportunities for management and leadership skills. Br Dent J 2013; 214: E2.

3. Willcocks S G. Exploring leadership in the context of dentistry in the UK. Leadersh Health Serv (BradfEngl) 2016; 29: 201-216.

4. Trathen A, Gallagher J E. Dental professionalism: definitions and debate. Br Dent J 2009; 206: 249-253.

5. Certosimo F. The servant leader: a higher calling for dental professionals. J Dent Educ 2009: 73: 1065-1068.

6. Wang Z, Liu Y, Liu S. Authoritarian leadership and task performance: the effects of leader-member exchange and dependence on leader. Front Bus Res China 2019; 13: 19.

7. Harms P D, Wood D, Landay K, Lester P B, Lester G V. Autocratic leaders and authoritarian followers revisited: A review and agenda for the future. Leadersh Quart 2018; 29: 105-122

8. Newsome P, Barrow C. Profitable dental practice: 8 strategies for building a practice that everyone loves to visit. London: CRC Press, 2014

9. De Hoogh A H, Den Hartog D N. Ethical and despotic leadership, relationships with leader's social responsibility, top management team effectiveness and subordinates' optimism: A multi-method study. Leadersh Quart 2008; 19: 297-311.

10. Schilling J. From ineffectiveness to destruction: A qualitative study on the meaning of negative leadership. Leadership 2009; 5: 102-128.

11. Harris R, Garner J, Perkins E. A discourse of disconnection - challenges to clinical engagement and collaborative dental commissioning. Br Dent J 2015; 218: 393-397.

12. Baker C. What is ethical marketing? BDJ In Pract 2019; 32: 20-21.

13. Bedi R, Wordley V. Education and training for dental leadership-A case study of the Senior Dental Leadership programme. J Dent 2019; 87: 36-39.

14. General Dental Council. Principles of dental team working. London: General Dental Council, 2006.

15. Hayer N, Wassif H S. A lonely business: reflections on the wellbeing and morale of dental teams. Br Dent J 2019; 226: 559-561.

16. Larbie J, Kemp M, Whitehead P. The mental health and well-being of UK dentists: a qualitative study. London: British Dental Association, 2017

17. FDI World Dental Federation. Leading the world to optimal oral health. Geneva-Cointrin: FDI World Dental Federation, 2015

18. McEwan D, Ruissen $G$, Eys M A, Zumbo B D, Beauchamp M R. The effectiveness of teamwork training on teamwork behaviours and team performance: a systematic review and meta-analysis of controlled interventions. PLoS One 2017; DOI: 10.1371/ journal.pone. 0169604.
19. Rousseau V, Aubé C, Savoie A. Teamwork behaviours: A review and an integration of frameworks. Small Group Res 2006; 37: 540-570.

20. Marks M A, Mathieu J E, Zaccaro S J. A temporally based framework and taxonomy of team processes. Acad Manage Rev 2001; 26: 356-376.

21. Stagnell S, Patel N, Allen Y, Shah S. The Way Forward for Dental Leadership. Prim Dent J 2017; 6: 62-65.

22. Chrislip D D, Larson C E. Collaborative leadership: How citizens and civic leaders can make a difference. San Francisco: Jossey-Bass Inc Pub, 1994

23. Green B N, Johnson C D. Interprofessional collaboration in research, education, and clinical practice: working together for a better future. J Chiropr Educ 2015; 29: $1-10$.

24. VanVactor J D. Collaborative leadership model in the management of health care. J Bus Res 2012; 65: 555-561.

25. Lawrence R L. Understanding collaborative leadership in theory and practice. New Direct Adult Cont Educ 2017 156: 89-96.

26. Herrero Babiloni A, Lam J T, Exposto F G et al. Interprofessional Collaboration in Dentistry: Role of physiotherapists to improve care and outcomes for chronic pain conditions and sleep disorders. J Oral Pathol Med 2020; 49: 529-537.

27. Brunton P. Leadership in modernising dental facilities. J Dent 2019; 87: 59-61.

28. Williams D M, Mossey P A, Mathur M R. Leadership in global oral health. J Dent 2019; 87: 49-54.

29. Migliorati C A, Madrid C. The interface between oral and systemic health: the need for more collaboration. Clin Microbiol Infect 2007; 13: 11-16.

30. British Dental Association. Sustainability in dentistry. 2020. Available at https://bda.org/about-the-bda/ campaigns/sustainable/Pages/Sustainability-indentistry.aspx (accessed November 2020).

31. Faculty of General Dental Practice. National dental organisations join forces to agree return-to-work guidance. 2020. Available online at https://www.fgdp. org.uk/news/national-dental-organisations-join-forcesagree-return-work-guidance (accessed November 2020).

32. Morris S. OCDO sets up group to tackle discrimination in dentistry. 2020. Available at https://www.dentistry. co.uk/2020/11/12/tackling-discrimination-dentistryocdo/ (accessed November 2020).

33. Tang W C, Kingsley K, Reinke R. Impact of Collaborative Leadership in Dental School Team Clinics. J Dent Educ 2019; 83: 1436-1444.

34. Valle-Oseguera C, Boyce E G. Dentists and Pharmacists: Paradigm Shifts and Interprofessional Collaborative Practice Models. J Calif Dent Assoc 2015; 43: 591-595.

35. Lo E C. Enhancing health care services through close collaboration between medical and dental professionals. Hong Kong Med J 2014; 20: 92-93.

36. Lau K T, John J, Eaton K A, Keightley A J. Service evaluation of the paediatric dental general anaesthesia service in NHS Lothian. Br Dent J 2020; DOI: 10.1038/ s41415-020-1982-z.

37. Marques P, Bernardo M, Presas P, Simon A. Corporate social responsibility in a local subsidiary: internal and external stakeholders' power. Euro Med J Bus 2019; 15: 377-393.

38. Mitchell R K, Lee J H. Stakeholder identification and its importance in the value creating system of stakeholder work. In Harrison J S, Barney B, Freeman R E, Phillips R A (eds) The Cambridge Handbook of Stakeholder Theory. pp 53-73. Cambridge: Cambridge University Press, 2019.

39. Bullock A, Firmstone V. A professional challenge: the development of skill-mix in UK primary care dentistry. Health Serv Manage Res 2011; 24: 190-195.

40. O'Dowd A. DIY orthodontics-safe, cheaper option or dangerous gamble? Br Dent J 2020; 228: 321-324.

41. Concannon T W, Meissner P, Grunbaum J A et al. A new taxonomy for stakeholder engagement in patientcentreed outcomes research. J Gen Int Med 2012; 27: 985-991.

42. Gnich W, Deas L, Mackenzie S, Burns J, Conway D I. Extending dental nurses' duties: a national survey investigating skill-mix in Scotland's child oral health improvement programme (Childsmile). BMC Oral Health 2014; 14: 1-13.
43. Anonymous. Why are dental nurse salaries so low? BDJ Team 2016: 3: 16152

44. Bissett G. 'Severe lack of support' - dental nurses speak out on the impact of COVID-19. 2020. Available at https://www.dentistry.co.uk/2020/09/09/dentalnurses-leaving-profession/ (accessed November 2020).

45. NHS Digital. Dentists' Working Patterns, Motivation and Morale - 2018/19 and 2019/20: Official Statistics. 2020. Available online at https://digital.nhs.uk/ data-and-information/publications/statistical/ dental-working-hours/2018-19-and-2019-20-workingpatterns-motivation-and-morale (accessed November 2020).

46. Singh P. Orthodontic allegations raised against registrants by the General Dental Council. Br Dent J 2016; 221: 291-294.

47. Makin J. Keep it local. 2020. Available at https://www. dentistry.co.uk/2020/03/30/keep-it-local/ (accessed November 2020).

48. Alves O M, Moreira J P, Santos P C. Developing community partnerships for primary healthcare: An integrative review on management challenges. Int J Healthc Manag 2020; 24: 1-9.

49. Ross M, Turner S. Direct access in the UK: what do dentists really think? Br Dent J 2015; 218: 641-647.

50. Kinsinger $F S$. Beneficence and the professional's moral imperative. J Chiropr Humanit 2009; 16: 44-46.

51. Mayer D M, Aquino K, Greenbaum R L, Kuenzi M. Who displays ethical leadership, and why does it matter? An examination of antecedents and consequences of ethical leadership. Acad Manag J 2012; 55: 151-171.

52. Zhu Y, Sun L Y, Leung A S. Corporate social responsibility, firm reputation, and firm performance: The role of ethical leadership. Asia Pac J Manag 2014; 31: 925-947

53. Northouse P G. Leadership: Theory and Practice. 6 th ed. Thousand Oaks: Sage Publications, 2013.

54. Odeneye A S, Hoon S N, Phlypo K S. Perceptions of Followers About Ethical Leadership and Attendant Effects on Organisational Success. J Soc Change 2018; 10: $61-70$

55. Kelleher M. The 'Uberization of orthodontics' - or how low can you go?. Dent Update 2016; 43: 606-607.

56. Westgarth D. Social media: A picture perfect storm? BD In Pract 2019; 32: 4.

57. Wertheimer M B. Pursuit of excellence: A forgotten quest? APOS Trend Orthod 2018; 8: 10-13.

58. Lewallen J, Behm-Morawitz E. Pinterest or Thinterest? social comparison and body image on social media. Soc Media Soc 2016; 2: 1-9.

59. Sampson A, Jeremiah H G, Andiappan M, Newton J T. The effect of viewing idealised smile images versus nature images via social media on immediate facial satisfaction in young adults: A randomised controlled trial. J Orthod 2020; 47: 55-64.

60. Chate R A. Truth or consequences: the potential implications of short-term cosmetic orthodontics for general dental practitioners. Br Dent J 2013; 215: 551-553.

61. Cannon S. Professional standards for cosmetic practice. London: The Royal College of Surgeons of England, 2013.

62. Sandler J. Patients. or 'profit centres'? J World Fed Orthod 2018; 7: 2-5.

63. Taylor S G, Pattie M W. When does ethical leadership affect workplace incivility? The moderating role of follower personality. Bus Ethics Quart 2014; 24: 595-616.

64. Anonymous. Accusations of racism have been made within Cardiff's School of Dentistry. BDJ Student 2020 27: 6 .

65. Trainor R. What the head of a university expects from the leadership of a dental school. J Dent 2019; 87: 62-65.

66. Gallagher J E, Morison S. Women in academic leadership: A chance to shape the future. J Dent 2019; 87: $45-48$

67. Clarkson J, Worthington $\mathrm{H}$. Leadership in evidence based dentistry. J Dent 2019; 87: 16-19.

68. Zahra FS, Dunton K. Learning to look from different perspectives - what can dental undergraduates learn from an arts and humanities-based teaching approach? Br Dent J 2017; 222: 147-150. 